\title{
Photosensitisation and photodynamic therapy of oesophageal, duodenal, and colorectal tumours using 5 aminolaevulinic acid induced protoporphyrin IX - a pilot study
}

National Medical Laser Centre, Department of Surgery, University College London Medical School, London

A J MacRobert

G A Buonaccorsi

$S M$ Thorpe

G M Spencer

S G Bown

Department of Clinical Pharmacology and Therapeutics, St

Mary's Hospital

Medical School,

London

A Gorchein

Department of Gastroenterology, Middlesex Hospital, London

A R W Hatfield

Department of

Gastroenterology,

Medical Centre for

Postgraduate

Education, Warsaw,

Poland

J Regula

Correspondence to Professor S G Bown National Medical Laser Centre, The Rayne Institute, 5 University Street, London WC1E 6JJ.

Accepted for publication 12 April 1994 J Regula, A J MacRobert, A Gorchein, G A Buonaccorsi, S M Thorpe, G M Spencer,
A R W Hatfield, S G Bown

\begin{abstract}
The first study of photodynamic therapy in the human gastrointestinal tract using 5 aminolaevulinic acid (ALA) induced protoporphyrin IX as the photosensitising agent is described. Eighteen patients with colorectal, duodenal, and oesophageal tumours were studied. After $30-60 \mathrm{mg} / \mathrm{kg}$ of ALA given orally, biopsy specimens of tumour and adjacent normal mucosa were taken 1-72 hours later. These specimens were examined by quantitative fluorescence microscopy for assessment of sensitisation with protoporphyrin IX. Ten patients were given a second dose of ALA a few weeks later and their tumours were treated with red laser light $(628 \mathrm{~nm})$. With $30 \mathrm{mg} / \mathrm{kg}$ ALA, the highest fluorescence values were detected in the duodenum and oesophagus, and the lowest in the large bowel. Doubling the ALA dose in patients with colorectal tumours gave protoporphyrin IX fluorescence intensities similar to those in patients with upper gastrointestinal lesions and improved the tumour:normal mucosa protoporphyrin IX sensitisation ratio. The treated patients showed superficial mucosal necrosis in the areas exposed to laser light. Six patients had transient rises in serum aspartate aminotransferases, two mild skin photosensitivity reactions, and five mild nausea and vomiting. In conclusion, photodynamic therapy with systemically administered ALA may be a promising technique for the treatment of small tumours and areas of dysplasia such as in Barrett's oesophagus.
\end{abstract}

(Gut 1995; 36: 67-75)

Keywords: photodynamic therapy, 5 aminolaevulinic acid, protoporphyrin IX.

Photodynamic therapy (PDT) is a promising non-thermal technique for producing localised necrosis with light after prior administration of a photosensitising drug. Necrosis is produced in tissues containing adequate concentrations of sensitiser and molecular oxygen upon exposure to light at an appropriate wavelength and dose by the sensitised generation of the highly cytotoxic singlet oxygen species. ${ }^{1}$ Ideally the photosensitiser should be selectively retained within the tumour to be destroyed with minimal retention in the surrounding normal tissues. Such high selectivity, however, is not attained with currently used photosensitisers (haematoporphyrin derivative and its purified versions) and therefore damage to normal tissues has to be considered, although this is acceptable provided that safe healing occurs. ${ }^{2}$ Damage induced by thermal techniques (Nd:YAG laser) or radiotherapy usually affects all layers of a viscus. This includes damage to collagen fibrils and smooth muscle, which can result in perforation or induce the formation of scar tissue and the development of stenoses. Animal studies suggest that damage produced by PDT is more selective, sparing collagen fibrils and hence permitting healing predominantly by regeneration. ${ }^{3}$ This implies that the mechanical integrity of the gastrointestinal wall is preserved but also that there is less risk of scarring. However this difference is not absolute. Clinical reports of PDT for oesophageal $^{4}$ and bladder $^{5}$ tumours have shown that it may cause strictures and scarring and detailed experimental studies on other organs (particularly the bladder ${ }^{6}$ ) have shown that even if healing in muscle is complete on light microscopy, muscle function may not entirely recover.

The present status of PDT is far from ideal. The problems of photosensitiser uptake by the target tissue are compounded by the associated cutaneous photosensitivity, which may persist for six weeks after the administration of haematoporphyrin derivatives. Further complications result because of the limited light penetration of the target issue in addition to difficulties with precise light delivery and monitoring.

5-Aminolaevulinic acid (ALA) is a naturally occurring intermediary in the haem synthetic pathway. This compound has recently been exploited as a new photosensitising agent or prodrug. ${ }^{7}$ ALA is metabolised at tissue level to the active compound, protoporphyrin IX, which is responsible for in vivo photosensitisation. Protoporphyrin IX accumulates within cells, after exogenous ALA administration, resulting from comparatively low activity of ferrochelatase, the enzyme responsible for the conversion of protoporphyrin IX to haem. Photosensitisation obtained in this way has been successfully used for PDT in vitro, ${ }^{7}$ in animal tumour models, ${ }^{910}$ and in humans after topical administration in the treatment of 
cutaneous basal cell carcinomas ${ }^{4}$ and after systemic administration for the treatment of tumours of the mouth. ${ }^{11}$

There are several advantages to using ALA induced protoporphyrin IX photosensitisation. Firstly, ALA, protoporphyrin IX, and other intermediates are rapidly eliminated from the body and hence the risk of skin photosensitivity is limited to one to two days. ${ }^{71112}$ Secondly, after the administration of ALA, protoporphyrin IX is preferentially accumulated in the mucosa of the normal gastrointestinal tract and to a much lesser extent in the submucosa and muscle layers, ${ }^{13}$ in contrast with haematoporphyrin derivative, which accumulates more in the submucosal vascular stroma. The ratio between large bowel mucosa and muscle can be as high as $10: 1 .{ }^{9}$ In view of the earlier remarks concerning the risk of perforation and scarring, it might be anticipated that more selective superficial mucosal damage occurs after ALA administration and appropriate light illumination with less risk of strictures. Thirdly, ALA seems to offer better selectivity in terms of uptake between tumour and normal tissue. ${ }^{9}$ Lastly, ALA can be given orally, providing an acceptable and convenient route of administration for patients. ${ }^{11-14}$

This knowledge has prompted us to study: (a) the tissue distribution of protoporphyrin IX fluorescence after oral administration of ALA, in patients with colorectal, oesophageal, and duodenal tumours; and (b) whether ALA, when given orally, is effective in inducing PDT necrosis in these patients upon irradiation with red light at $628 \mathrm{~nm}$.

\section{Patients and methods}

Eighteen patients with gastrointestinal tumours referred for laser treatment were included in this study. There were 12 men and six women with a median age of 79 years; range 38-93. They were divided into three groups: colorectal (eight patients), seven with adenocarcinomas and one with an adenoma; duodenal (six patients), three with duodenal adenomas and three with papilla of Vater adenocarcinomas; oesophageal (four patients), three with adenocarcinomas and one with squamous cell carcinoma. The group we studied first was the colorectal one, because of easy access to the lesions and the possibility of taking serial biopsies, even every one to two hours, to assess the temporal kinetics of protoporphyrin IX accumulation using fluorescence microscopy. Two of the patients with duodenal adenomas had familial adenomatous polyposis and a history of colectomy. All patients with papilla of Vater adenocarcinomas had previously had biliary stents inserted to relieve their jaundice before this study began. All patients were either unsuitable for surgery because of advanced age or severe cardiorespiratory disease or were not considered suitable for operation at the time of referral (patients with benign tumours).

After informed consent was obtained patients were given 5-ALA by mouth dissolved in 5-10 $\mathrm{ml}$ of orange juice at doses of $30 \mathrm{mg} / \mathrm{kg}$ or $60 \mathrm{mg} / \mathrm{kg}$. The first three colorectal patients were given ALA as a bolus and the remainder received it as a fractionated dose in six equal portions at hourly intervals. This fractionated dose was chosen on the basis of established pharmacokinetic principles ${ }^{15}$ to maintain a longer period of high blood concentrations of ALA. The time intervals were based on information from a Finnish study defining the plasma ALA half life $\left(\mathrm{T}_{1 / 2}\right)$ as 50 minutes with a peak plasma concentration at one hour after oral administration. ${ }^{14}$ All patients were kept in a darkened room for 24 hours after administration of ALA. Flexible sigmoidoscopy with biopsy specimens from the tumour and adjacent normal mucosa before and 1 to 9,48 , and 72 hours after ALA administration were performed in the initial group of patients with colorectal tumours. Subsequent oesophageal and duodenal group patients had upper gastrointestinal endoscopy only once, six hours after the first of the fractionated ALA doses, as it was considered unethical to undertake serial procedures in these groups. One of the patients with duodenal adenomas, familial adenomatous polyposis, and previous colectomy with ileorectal anastomosis underwent both upper endoscopy and sigmoidoscopy six hours after the first ALA dose. In oesophageal adenocarcinomas two sets of normal mucosal biopsy specimens were taken; from normal squamous epithelium above the tumour and from mucosa below the lesion (glandular epithelium). Most of the sigmoidoscopies were performed without sedation, and the oesophageal and duodenal examinations were carried out with the routine sedation used for diagnostic procedures. The specimens obtained during endoscopic examinations were immediately frozen in a bath of isopentane (BDH Ltd, UK) precooled in liquid nitrogen, and then stored in liquid nitrogen for subsequent fluorescence microscopy studies. The technique of quantitative fluorescence microscopy, described in detail elsewhere, ${ }^{9}$ was performed on $10 \mu \mathrm{m}$ thick frozen sections. An inverted microscope (IMT-2, Olympus) with epifluorescence and phase contrast attachments was used with a mounted charged coupled device camera (Wright Instruments) to obtain fluorescence images of the selected area of the section. Fluorescence was excited with an $8 \mathrm{~mW}$ helium neon laser emitting at $632.8 \mathrm{~nm}$ and was detected in the range 660 to $710 \mathrm{~nm}$ using a combination of bandpass (Omega Optical) and longpass (Schott RG655) filters. Images were acquired with a $10 \mathrm{X}$ objective and processed by an IBM PC computer to permit digital quantification of the fluorescence intensity from areas of interest (in counts/pixel). After fluorescence images were recorded the tissue sections were fixed in formalin and stained with haematoxylin and eosin for comparative light microscopy studies, which permitted precise identification of fluorescing structures. Specimens obtained from the initial group of patients taken before ALA administration were also examined with 

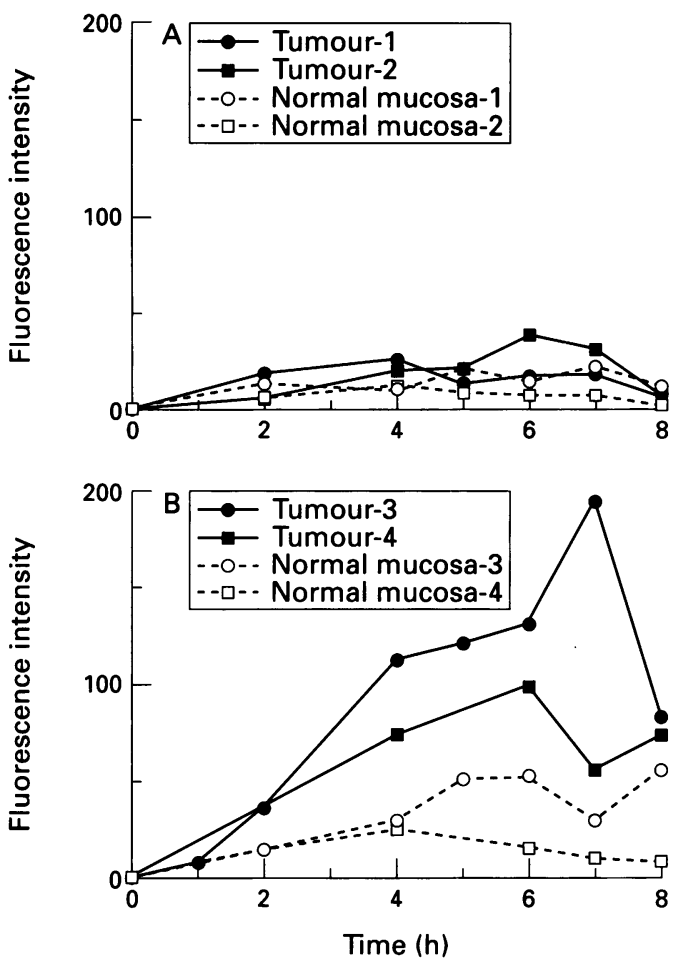

Figure 1: Microfluorimetric intensities (counts per pixel) in biopsy specimens of colorectal adenocarcinomas and normal mucosa in two patients after $30 \mathrm{mg} / \mathrm{kg}(A)$ and in another two patients after $60 \mathrm{mg} / \mathrm{kg}(B)$ of $A L A$ orally.

this technique to quantify autofluorescence, which did not exceed 5 counts/pixel with little variation noted between normal mucosa and tumour. The total background reading included a 10 count/pixel computer generated offset and luminescence from optical components (20 counts/pixel). Fluorescence intensity values were measured in areas of interest, corrected for autofluorescence, and expressed as a mean of at least four measurements obtained from two biopsy samples.

Venous blood samples were collected before and at 24 hours (in some patients also 72 hours) after ALA ingestion for routine biochemistry examination (urea, creatinine, sodium, potassium, albumin, alkaline phosphatase, bilirubin, and asparatate aminotransferase) and a full blood count. Twelve patients had additional blood samples, collected for determination of plasma ALA concentrations at a range of times between one and 24 hours after the first dose of ALA. ALA plasma concentrations were determined using a modified colorimetric method of HaegerAronsen. ${ }^{16} \mathrm{Blood}$ for this assay was collected into plastic tubes containing EDTA and separatedplasma stored frozen at below $-18^{\circ} \mathrm{C}$ until assessed.

Photodynamic therapy was performed on a different occasion, usually one to two months after the test dose of ALA, in 10 of our patients: in all three with papilla of Vater adenocarcinomas, two patients with duodenal adenomas, three of those with oesophageal cancer, and two from the colorectal group. A gold vapour laser emitting at $628 \mathrm{~nm}$ was used in all patients except one from the colorectal group who was treated with a copper vapour pumped dye laser $(630 \mathrm{~nm})$. The light was delivered by fibres introduced through the biopsy channel of the endoscope (Olympus, CF 20S, GIF 1 T20 or JF T20) either interstitially with a $200 \mu \mathrm{m}$ bare fibre or intraluminally with a $1 \mathrm{~cm}$ long diffuser fibre (PDT Systems, California, USA). The treatment commenced six hours after the first of the series of six fractionated ALA doses given at hourly intervals. We applied either 50 or $100 \mathrm{~J}$ (50 or $100 \mathrm{~mW}$ for 1000 seconds) at two to seven spots with bare fibres inserted into the tumour to 1-2 $\mathrm{mm}$. In certain cases surface irradiation was used (up to $100 \mathrm{~J} / \mathrm{cm}^{2}$ ) using a cylindrical diffuser fibre positioned intraluminally (up to $570 \mathrm{~mW} / \mathrm{cm}$ of the fibre). For lesions longer than $1 \mathrm{~cm}$, the diffuser fibre was positioned successively at several points at $1 \mathrm{~cm}$ intervals along the lesion to ensure adequate light delivery to all areas. One patient with a papilla of Vater adenocarcinoma had the diffuser fibre inserted into the transparent, polyethylene biliary stent to illuminate the ampullary tumour from inside. All treated patients underwent control endoscopy with biopsy specimens for histological examination usually six days after PDT (range: 3-11), and subsequently on clinical grounds.

Local ethical committee approval and a Medicines Control Agency 'Doctors and Dentists Exemption from Clinical Trials Certificate' to use ALA were granted for this study.

\section{Results}

\section{FLUORESCENCE MICROSCOPY STUDIES}

Recent studies with animal and patient tissues after systemic ALA administration using chemical extraction and emission spectroscopy techniques have shown that the porphyrin content comprises at least $95 \%$ protoporphyrin IX. ${ }^{11} 17$ Good correlation has been found between chemically extracted values of protoporphyrin IX and microfluorimetric measurements using the highly reproducible technique used here in tissue layers of the gastrointestinal tract. ${ }^{17}$ In rat gastric and colonic mucosa, a fluorescence intensity of 100 counts/pixel (recorded under the same calibration conditions) was found to correspond to about 5-6 $\mu \mathrm{g}$ of protoporphyrin IX per gram of tissue. The specimens examined here from the normal tissues were too small for accurate determination of protoporphyrin IX content using chemical extraction and consequently we have relied solely on the microfluorimetric technique for assessment of protoporphyrin IX sensitisation. Furthermore with this technique we could monitor changes in the microscopic protoporphyrin IX distribution, which would not have been apparent from a gross extraction technique.

Specimens from the first two colorectal patients after receiving a bolus dose of $30 \mathrm{mg} / \mathrm{kg}$ ALA exhibited fluorescence intensities above background values, as integrated over the microscopic image $(880 \times 550 \mu \mathrm{m})$, thus confirming the possibility of inducing 


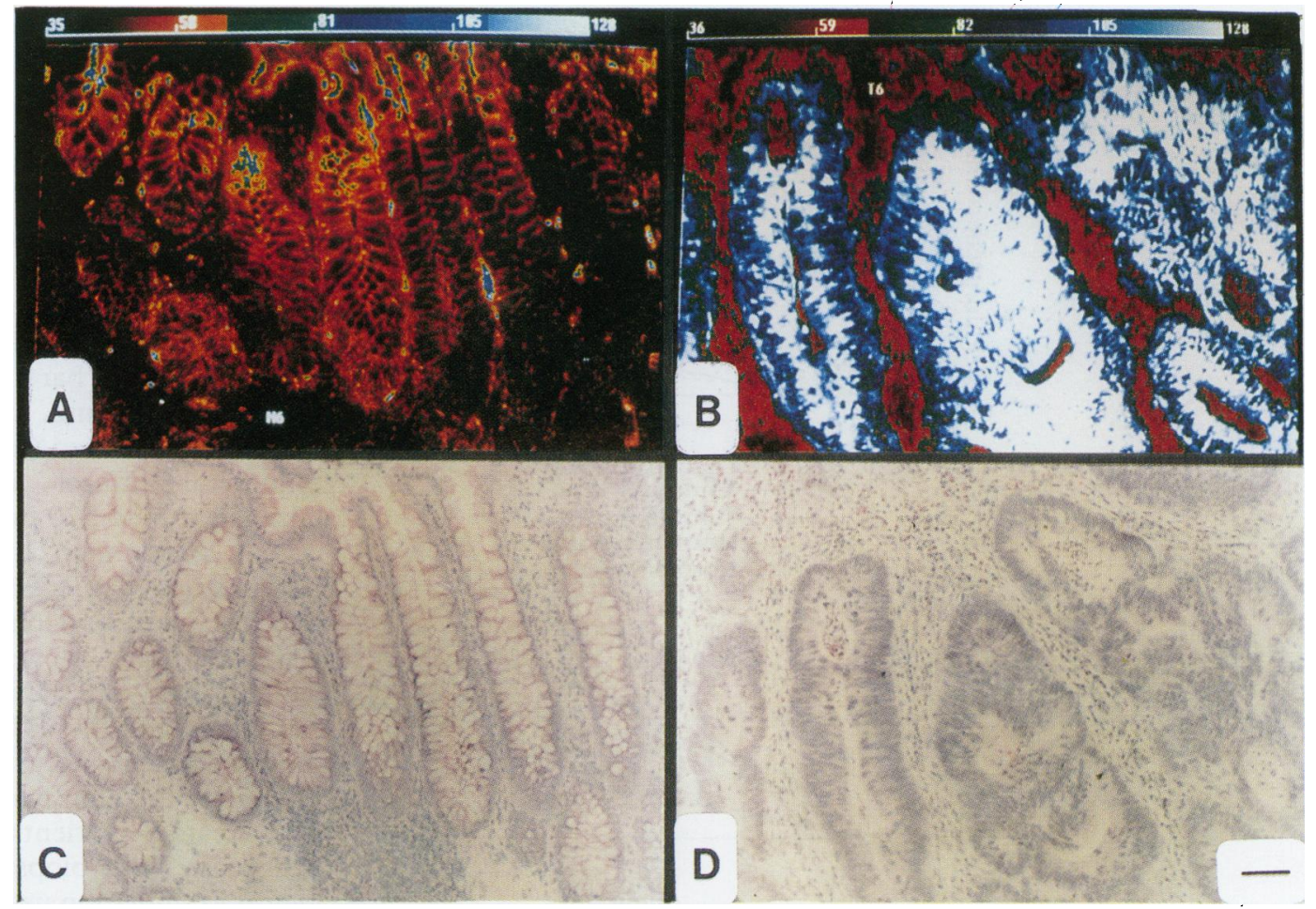

Figure 2: Fluorescence microscopy false colour coded images of the normal colorectal mucosa (A) and adenocarcinoma (B) in a patient six hours after $60 \mathrm{mg} / \mathrm{kg}$ of $A L A$. Scale indicating fluorescence intensity is shown in upper parts of images; the highest fluorescence is represented by white, the lowest by black. Scale: bar represents $80 \mu \mathrm{m}$. Corresponding haematoxylin and eosin stained sections shown in (C) and (D).

protoporphyrin IX accumulation in the large bowel after oral administration of ALA. The intensities seen were still comparatively low, however, with peak values not exceeding 39 counts per pixel between four and six hours after ALA (Fig 1A). The subsequent two colorectal patients were given $60 \mathrm{mg} / \mathrm{kg}$, one of them with a fractionated dose. The fluorescence intensities obtained in these cases were much higher, reaching nearly 200 counts/pixel, with good selectivity evident between tumour and normal mucosa (Fig 1B). From the experimental studies of animal tissues including duodenal tumours, ${ }^{17} 200$ counts/pixel corresponds to about $10 \mu \mathrm{g} / \mathrm{g}$ of protoporphyrin IX with the assumption that similar protopor-
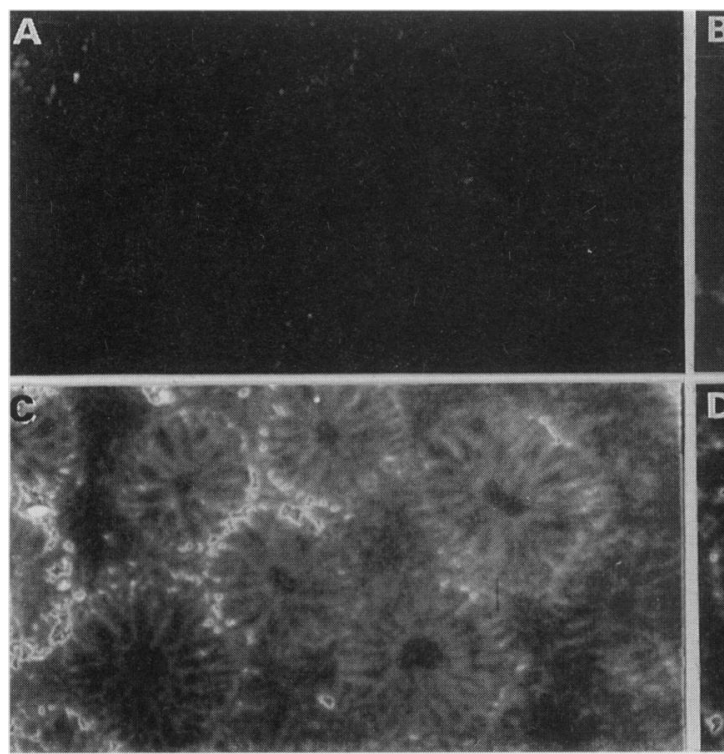

Figure 3: Fluorescence microscopy images of the normal rectal mucosa before administration of $A L A(A)$ and one hour $(B)$, four hours (C), and seven hours (D) after $60 \mathrm{mg} / \mathrm{kg}$ of $A L A$. Scale: bar represents $80 \mu \mathrm{m}$.

phyrin IX fluorescence efficiencies apply to each tissue. Five other patients with colorectal tumours (including one with familial adenomatous polyposis and coexisting duodenal adenomas - from duodenal group) received fractionated administration of $30 \mathrm{mg} / \mathrm{kg}$ or 60 $\mathrm{mg} / \mathrm{kg}$ ALA, or both, but less frequent endoscopies than the initial patients. High protoporphyrin IX fluorescence intensities with this mode of ALA administration were obtained in the large bowel only after a total dose of 60 $\mathrm{mg} / \mathrm{kg}$ with peak values found at six hours. Additionally, it was only the higher dose that resulted in good selectivity between tumour and normal mucosa with a ratio of about 5:1 (Fig 2). These results in terms of fluorescence
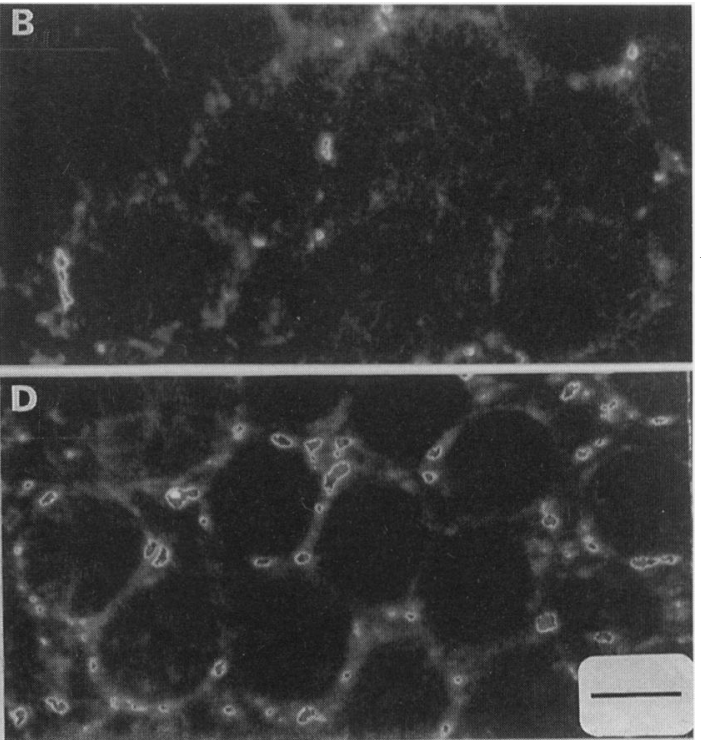
TABLE I Fluorescence intensities in biopsy specimens from the oesophagus, duodenum, and large bowel using 30 or 60 $\mathrm{mg} / \mathrm{kg}$ of $A L A$ given as six fractionated hourly doses

\begin{tabular}{llc}
\hline & \multicolumn{2}{l}{$\begin{array}{l}\text { Median fluorescence intensity (range) } \\
\text { six hours after first dose }\end{array}$} \\
\hline Tissue (ALA dose) & Tumour & Normal mucosa \\
\hline $\begin{array}{c}\text { Oesophagus } \\
(30 \mathrm{mg} / \mathrm{kg})\end{array}$ & $104(58-217)$ & $88(27-100)$ \\
$\begin{array}{c}\text { Duodenum } \\
(30 \mathrm{mg} / \mathrm{kg})\end{array}$ & $116(90-568)$ & $17(16-18)^{\star}$ \\
$\begin{array}{c}\text { Large bowel } \\
(30 \mathrm{mg} / \mathrm{kg})\end{array}$ & $10(4-39)$ & $7(5-14)$ \\
$\begin{array}{c}\text { Large bowel } \\
(60 \mathrm{mg} / \mathrm{kg})\end{array}$ & $87(45-196)$ & $15(8-29)$ \\
\hline
\end{tabular}

*These values were obtained from the normal mucosa below the adenocarcinomas (cardia region, glandular epithelium).

intensities and tumour selectivity are very similar to those found previously for an experimental colorectal tumour induced by dimethylhydrazine in rats given intravenously $200 \mathrm{mg} / \mathrm{kg}$ ALA. ${ }^{9}$ In one patient with a short small intestine and receiving total parenteral nutrition even the $60 \mathrm{mg} / \mathrm{kg}$ dose produced only weak protoporphyrin IX fluorescence and the lowest plasma ALA concentrations. At longer times, seven to nine hours, it was apparent in tumour biopsy specimens that some fluorescence was also present in the glandular lumen showing that the protoporphyrin IX was excreted from the glands.

The earliest time point at which specimens were taken in patients from the colorectal group was one hour after ALA administration. In normal mucosa a very weak fluorescence seemed to be associated with the lamina propria adjacent to the glands at this time (Fig 3). Later, between two and seven hours, fluorescence activities reached maximal values in the glands and seemed to be mainly intracellular. After seven to nine hours the glandular fluorescence was considerably reduced but still visible in the lamina propria. In those patients

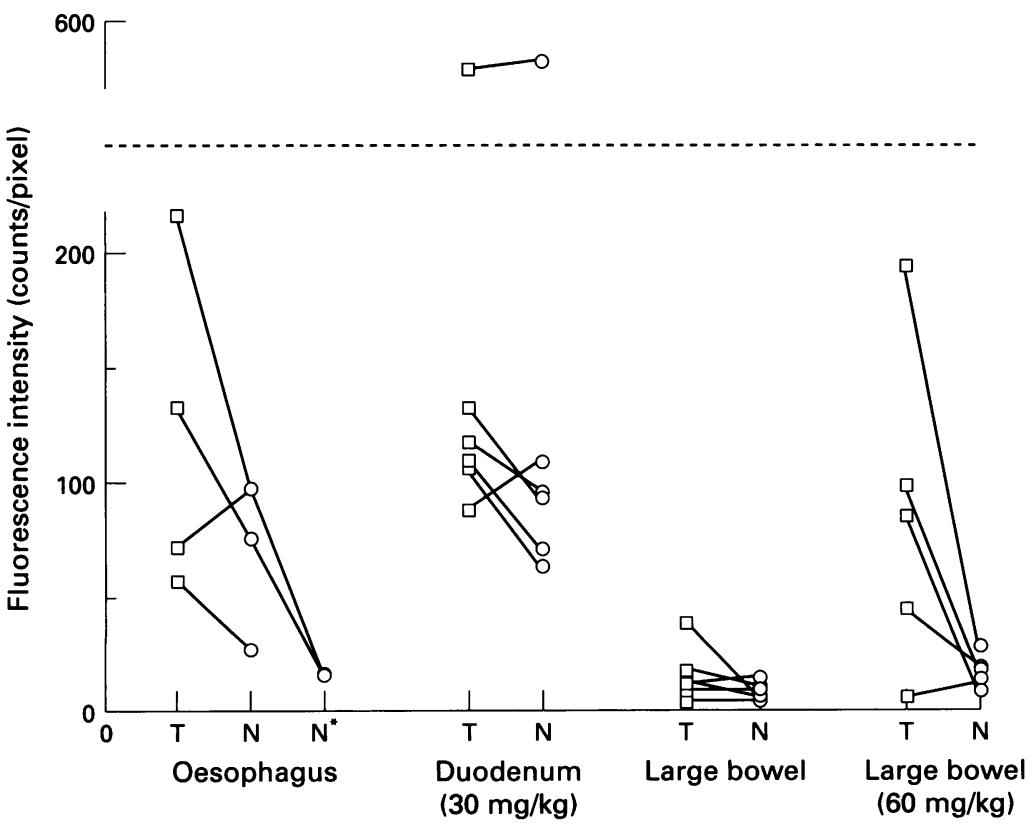

Figure 4: Fluorescence intensities in biopsy specimens of oesophageal, duodenal, and colorectal tumours $(T)$ and normal mucosa $(N)$ after fractionated administration of 30 $\mathrm{mg} / \mathrm{kg}$ or $60 \mathrm{mg} / \mathrm{kg}$ of $A L A$ - six hours after first of series of six doses. The lines connect values for individual patients. In three oesophageal patients both squamous normal mucosa and glandular epithelium from cardia region $\left(N^{\star}\right)$ are presented.
TABLE II Plasma ALA concentrations ( $\mu$ moll) in three patients with fractionated $30 \mathrm{mg} / \mathrm{kg}$ dose $\mathrm{v}$ time after first dose

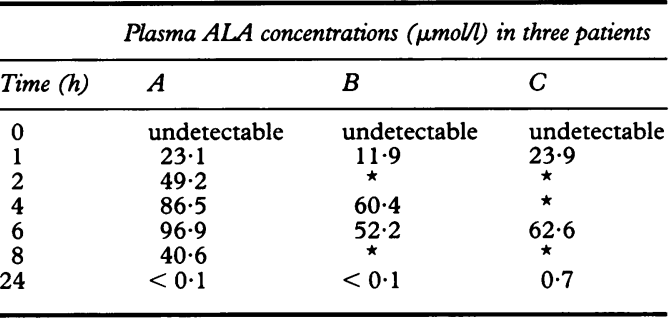

The higher residual concentration at 24 hours for patient $C$ may result from his impaired renal function. ${ }^{\star}$ No specimens taken at that time.

in whom colorectal biopsy specimens were taken at time points as late as 48 and 72 hours, fluorescence activities in both tumour and normal mucosa had returned to background values.

All patients from the oesophageal and duodenal groups were given $30 \mathrm{mg} / \mathrm{kg}$ ALA in fractionated doses and biopsy specimens were taken six hours after administration started. Tumour and normal tissue fluorescence intensities were similar and quite high in both organs, much higher than after a bolus $30 \mathrm{mg} / \mathrm{kg}$ dose and comparable with those after $60 \mathrm{mg} / \mathrm{kg}$ doses in the colorectal patients. Table I gives median values and ranges and Fig 4 shows paired individual readings from all patients. One of the patients with familial adenomatous polyposis and duodenal adenomas had extremely high fluorescence intensities in both duodenal adenomas and normal duodenal mucosa. The reason is not clear. The patient with duodenal adenomas, familial adenomatous polyposis, and an ileorectal anastomosis that had simultaneous sigmoidoscopy and duodenoscopy had much higher fluorescence in the duodenum than in the rectal mucosa confirming the tendency seen in the whole group of our patients.

\section{PLASMA ALA CONCENTRATIONS}

Table II gives plasma ALA acid concentrations determined in three of our patients during fractionated administration of $30 \mathrm{mg} / \mathrm{kg}$ with blood samples taken at one to 24 hours after the first ALA dose. The values are consistent with each fraction being given orally at time intervals close to the half life $\left(T_{1 / 2}\right)$ with a plasma plateau concentration being reached after about five doses. ${ }^{15}$ The mean plasma ALA concentration in 11 patients six hours after a fractionated dose of $30 \mathrm{mg} / \mathrm{kg}$ was $63 \mu \mathrm{mol} / 1$ (standard deviation: $33 \mu \mathrm{mol} / \mathrm{l}$ ). The values in two patients six hours after $60 \mathrm{mg} / \mathrm{kg}$ also as a fractionated dose were $116 \mu \mathrm{mol} / 1$ and $205 \mu \mathrm{mol} / 1$.

\section{PHOTODYNAMIC THERAPY}

Ten patients received photodynamic therapy after prior ALA sensitisation (three oesophageal, five duodenal, and two rectal patients). In eight of them, application of light was comparatively easy and resulted in endoscopic and histological confirmation of superficial mucosal necrosis. Macroscopically, 


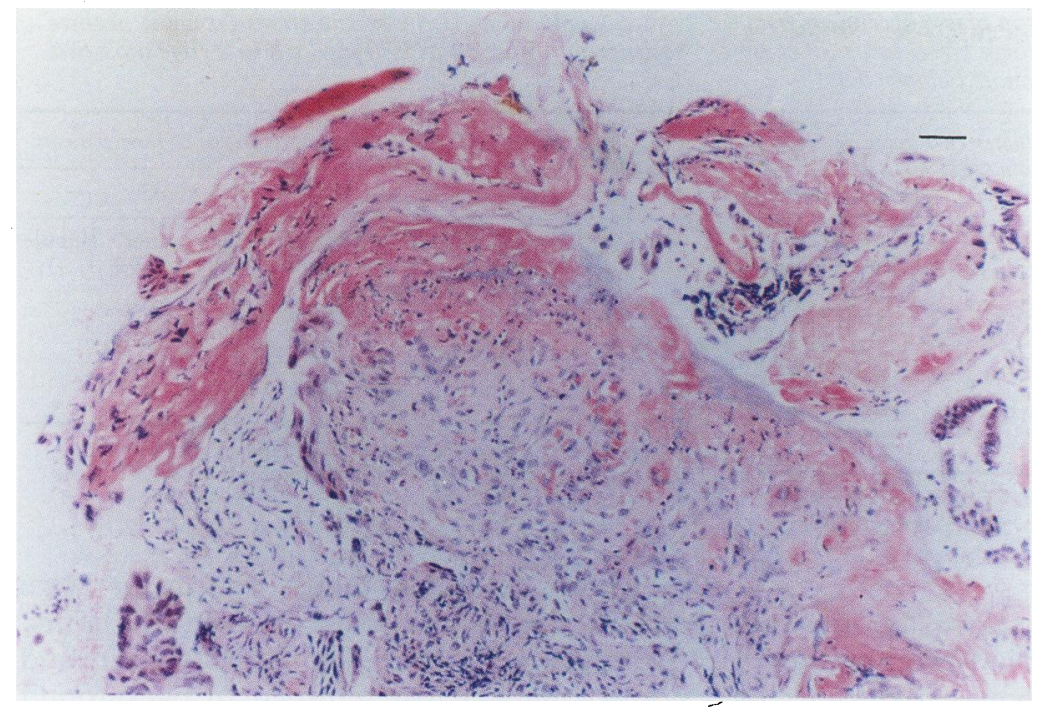

Figure 5: Superficial necrosis in a patient with papilla of Vater adenocarcinoma after photodynamic therapy using $A L A$ as a photosensitiser. Scale: bar represents $50 \mu \mathrm{m}$.

tumours were covered with whitish necrotic material and histologically, necrosis with fibrinous exudate was seen. It was difficult to assess the depth of necrosis, because of possible sloughing of necrotic tissue and thus any value given is probably an underestimate of the extent of damage. On the histological slides, however, it was assessed as at least $0.5 \mathrm{~mm}$ (Fig 5). In two of our treated patients no PDT damage could be detected either on macroscopic or microscopic grounds. One of them, an oesophageal adenocarcinoma treated early on in our experience, received only $50 \mathrm{~J}$ in total applied to his lesion and this dose of light was most probably insufficient to produce necrosis. A similar explanation may account for the lack of necrosis in a second case with a carcinoma of the papilla of Vater where proper positioning of the diffuser fibre was difficult because of a deformed duodenum. Table III gives details of the light delivery system used in each case and the results obtained.

\section{SIDE EFFECTS}

There were no complications of endoscopic procedures and patients from the colorectal group cooperated well during repeated sigmoidoscopies. The side effects found were probably related to ALA administration: two patients had mild skin photosensitivity reactions between 24 and 48 hours after ALA

TABLE III Tumour characteristics, light delivery methods, and results of photodynamic therapy treatment

\begin{tabular}{cllll}
\hline Patient no & Tumour type and length $(\mathrm{cm})$ & Fibre type & Energy//Irradiance & Effect \\
\hline 1 & Papilla of Vater cancer (1.5) & Diffuser & $100 \mathrm{~J} / \mathrm{cm}^{2}$ & Necrosis \\
2 & Papilla of Vater cancer (2) & Diffuser & $75 \mathrm{~J} / \mathrm{cm}^{2}$ & Necrosis \\
3 & Papilla of Vater cancer (3) & Diffuser & $75 \mathrm{~J} / \mathrm{cm}^{2}$ & No effect \\
4 & Duodenal adenoma (2) & Diffuser & $75 \mathrm{~J} / \mathrm{cm}^{2}$ & Necrosis \\
and & Duodenal adenoma (1) & Bare/2 spots & $100 \mathrm{~J} \mathrm{per} \mathrm{spot}$ & Necrosis \\
5 & Duodenal adenoma (2) & Bare/2 spots & $50 \mathrm{~J} \mathrm{per} \mathrm{spot}$ & Necrosis \\
6 & Oesophageal cancer (2) & Bare/2 spots & $100 \mathrm{~J} \mathrm{per} \mathrm{spot}$ & Necrosis \\
7 & Oesophageal cancer (1) & Bare/2 spots & $50 \mathrm{~J} \mathrm{per} \mathrm{spot}$ & No effect \\
8 & Oesophageal cancer (1) & Bare/7 spots & $50 \mathrm{~J}$ per spot & Necrosis \\
9 & Colorectal cancer (2) & Bare/2 spots & $50 \mathrm{~J}$ per spot & Necrosis \\
10 & Colorectal adenoma (1.5) & Bare/7 spots & $50 \mathrm{~J}$ per spot & Necrosis \\
\hline
\end{tabular}

Patient 1 had the fibre inserted into the transparent stent. Patient 4 had two different lesions treated on different occasions. administration, after leaving their darkened room, but experienced no problems beyond 48 hours; mild nausea and occasional vomiting occurred in five patients within the first 12 hours of receiving ALA and in six patients transient increases of serum aspartate aminotransferase (AST) activities were seen. AST abnormalities were seen in two thirds of patients given $60 \mathrm{mg} / \mathrm{kg}$ ALA and in one fifth of patients given $30 \mathrm{mg} / \mathrm{kg}$. In three patients, the AST values were three to five times normal and in the three other patients, were less than twice the upper limit of normal. In all three patients with abnormal AST activities, in whom blood was collected 72 hours after ALA administration, the raised values had returned to normal. AST abnormalities were accompanied by slight increases in plasma bilirubin concentration (three patients), $\gamma$-glutamyltransferase (two patients), and plasma alkaline phosphatase (one patient), but these never exceeded more than twice the upper limit of normal values. There was no evidence that repeated exposures to ALA increased the rise in AST: of the six patients with increased AST activities after the first ALA treatment, only one showed increased activities after another treatment.

\section{Discussion}

Photodynamic therapy for gastrointestinal malignancy with haematoporphyrin derivative as a sensitiser has been used empirically in a small number of centres particularly in the oesophagus, stomach, and rectum. ${ }^{18-23}$ Eradication of small tumours had occasionally been reported, but most patients have been those with advanced cancers for whom PDT is probably not appropriate. Current evidence suggests that PDT is more suitable for small volumes of tumour.22 Other problems have included a failure to match the treatment parameters to the depth of tumour necrosis required. Perforations, fistulas, post-treatment stenoses, and haemorrhage were also reported, but these probably resulted from inappropriate patient selection and, in some cases, from excessive laser irradiances leading to thermal rather than solely PDT induced effects. ${ }^{4} 182224$

It is generally accepted that haematoporphyrin derivatives are far from being ideal photosensitisers and that they have a considerable risk of causing prolonged skin photosensitivity. ${ }^{25} 5$ Aminolaevulinic acid as used in this study is one of the newest drugs considered for use in PDT - as it is metabolised to the active protoporphyrin IX moiety, ALA is in effect a 'prodrug'. The main advantages are: quick elimination from the body with only $24-48$ hours risk of skin photosensitivity and preferential photosensitisation in the mucosa of hollow organs as opposed to the muscle layers, so that epithelial tumours can be destroyed with less risk to deeper layers. ${ }^{9}$

This is the first report of photodynamic therapy in the human gastrointestinal tract using ALA. We have shown that after oral administration of ALA, protoporphyrin IX can 
be detected in all tissues studied (normal and neoplastic). There are two possible routes for tissue sensitisation after ALA administration: protoporphyrin IX can be synthesised in situ from the ALA diffusing from the bloodstream; alternatively, high concentrations of protoporphyrin IX produced in the liver are rapidly excreted with the bile into the gastrointestinal tract where it may be absorbed locally, or protoporphyrin IX synthesised in the liver may enter the systemic circulation directly. The in situ protoporphyrin IX production is reported in tissue culture studies, ${ }^{8}$ while the possibility of enterohepatic circulation of protoporphyrin IX is described in animal and human studies. ${ }^{26-29}$ Our earliest fluorescence images obtained one hour after ALA administration point to the presence of protoporphyrin IX fluorescence in the lamina propria at the peripheries of the glands although at this resolution it is difficult to discern the precise localisation. If fluorescence is present in the lamina propria at this time point this might suggest a systemic (for example, enterohepatic) origin for protoporphyrin IX. At later times up to six hours intracellular localisation of fluorescence in the glands clearly dominated consistent with in situ synthesis; in the biopsy specimens obtained seven to nine hours after ALA, extraglandular fluorescence was evident, which was probably caused by excretion of protoporphyrin IX from the cells. A recent in vitro study of epithelial cells cultured with ALA has also found evidence of protoporphyrin IX efflux. ${ }^{30}$ These microscopic findings of time dependent redistribution of protoporphyrin IX have important implications for the use of in vivo fluorescence monitoring using a fibre optic probe, which may be necessary in view of the significant variation in protoporphyrin IX sensitisation between patients. This macroscopic technique has the advantage of sampling larger volumes of tissue but may give misleading data on the temporal protoporphyrin IX tumour pharmacokinetics at longer times when a significant proportion of protoporphyrin IX is extracellular and presumably less photoactive - estimation of the optimum treatment time may therefore be compromised. Another advantage of the microfluorimetric technique described here using thin biopsy sections is that it is independent of variations in optical properties between tumour and normal mucosa that affect in vivo measurements. Nevertheless these techniques will probably prove complementary as discussed elsewhere. ${ }^{31}$

The dose of $30 \mathrm{mg} / \mathrm{kg}$ was effective in giving high fluorescence intensities in both duodenum and oesophagus but with comparatively poor selectivity between tumour and normal mucosa. With the colon and rectum, however, only weak fluorescence could be seen after this dose. Increasing the dose to $60 \mathrm{mg} / \mathrm{kg}$ resulted in high fluorescence mainly in the tumour tissue and much less in the normal mucosa although the higher dose was only given to patients with colonic tumours. The differences in fluorescence intensity between upper and lower gastrointestinal tract as well as between colorectal tumour and normal mucosa are difficult to explain. The easiest explanation is that the different types of cells have different metabolic rates and thus different requirements for haem and accompanying enzyme activities. In particular, it has already been reported that tissues differ in the activity of ferrochelatase, which catalyses the incorporation of iron into protoporphyrin IX to produce haem. Its activity is generally lower in tumours than in normal tissues, which could account for better accumulation of protoporphyrin IX in tumour than in normal cells after exogenous ALA administration. ${ }^{32}$ Conversely, activities of another haem biosynthesis enzyme, porphobilinogen deaminase, are reported in some cases to be enhanced in tumour. ${ }^{33}$ There have been several reports of higher endogenous porphyrin accumulation in patients (without administration of exogenous ALA), which may well be explained by abnormal activities of haem enzymes. ${ }^{33}$ Some variation in enzyme activities of different malignant cell populations within the tumour is possible and a potential advantage of fractionating the ALA dose is that any asynchrony in protoporphyrin IX accumulation may in part be averaged out. Better protoporphyrin IX accumulation in the duodenum than in the large bowel could also be explained by local absorption of protoporphyrin IX excreted with the bile. This could not be the case for the oesophagus, however, where fluorescence intensities were similar to those in the duodenum.

The results of the photodynamic treatment in our patients in whom delivery of light was sufficient confirm the possibility of inducing necrosis after ALA sensitisation. The necrosis has to be described as being superficial, and it is not clear why deeper necrosis was not seen in the tumours treated when deeper necrosis has been reported using Photofrin as the sensitiser. ${ }^{22} \mathrm{~A}$ higher rate of photobleaching of protoporphyrin IX during treatment may be a contributory factor and we intend to examine biopsy specimens taken immediately after laser irradiation. It is not surprising that necrosis in normal tissue adjacent to the tumours is superficial as our earlier studies showed much greater sensitisation of gastrointestinal mucosa compared with the underlying submucosa and muscular layers. This suggests that PDT with ALA is probably more appropriate for superficial lesions, such as areas of high grade dysplasia in Barrett's oesophagus or possibly in long standing ulcerative colitis. Using haematoporphyrin derivative based photosensitisers there have been recent reports of using PDT for Barrett's oesophagus. ${ }^{44}$ Preliminary results suggest successful destruction of Barrett's mucosa with re-epithelialisation by normal squamous epithelium, which may decrease the risk of cancer in that group of patients. Using this sensitiser, however, stenosis of the oesophagus occurred, which we would expect to avoid with ALA because of its tendency to produce photosensitisation preferentially in the mucosa and not in deeper layers of the gastrointestinal wall. ${ }^{13}$ Furthermore, 
treatment with ALA can be repeated after a week or two as the drug is quickly eliminated from the body, while repeated administration of haematoporhyrin derivative sensitisers at intervals of less than three months should be avoided because of the risk of cumulative skin photosensitivity. Further studies to evaluate the possibility of using ALA induced protoporphyrin IX for PDT in Barrett's oesophagus are warranted.

Fractionated dosage in our patients was chosen to avoid post-bolus high peak concentrations of plasma ALA and the associated excretion of large amounts in urine. ${ }^{12}$ We were able to produce plateau concentrations of ALA by giving it at intervals roughly corresponding to the half life $\left(\mathrm{T}_{1 / 2}\right)$ previously reported to be 50 minutes. ${ }^{14}$ These concentrations were in the range of $8-205 \mu \mathrm{mol} / 1$ at six hours from the start of the fractionated dosage. These values are much higher than in normal subjects (where ALA cannot be detected by the colorimetric method we used), which have been determined by more sensitive methods to be in the range of $0.02-0.27 \mu \mathrm{mol} / 1 .{ }^{35} \mathrm{In}$ patients with hereditary acute hepatic porphyrias the most severe forms of neurovisceral manifestations, including respiratory paralysis, have been described at maximum plasma concentrations of 9-12 $\mu \mathrm{mol} / 1 .^{35}$ Although the plasma concentration of ALA in our patients was up to 20 times higher, this was associated only with mild nausea and occasional vomiting. Thus even exposure of patients to plasma ALA concentrations of such unprecedented height, albeit for comparatively short times, did not induce specific porphyric symptoms, which is consistent with current thought that ALA is probably not responsible for the clinical manifestations of the acute porphyria attack. Skin photosensitivity is a lifelong problem with some porphyrias (for example, protoporphyria) and is also the limiting factor in wider use of haematoporhyrin derivative for PDT. Any transient effects were avoided in our patients by keeping them in subdued lighting for 24 hours after administration of ALA. Only mild reactions were noticed in two patients on the second day after ALA. The increase in aspartate aminotransferase activities were slightly more worrying, although they were only transient and did not cause any clinical problem.

In summary, we have evaluated the possibility of using ALA as a photosensitising agent for PDT in the gastrointestinal tract. After $30 \mathrm{mg} / \mathrm{kg}$ ALA by mouth, protoporphyrin IX fluorescence was seen in all tissues studied, with greater intensity evident in the oesophagus and duodenum than in the colon although tumour selectivity was minimal. Much better selectivity was obtained using $60 \mathrm{mg} / \mathrm{kg}$ but only the colon was studied using this dose. Irradiation with red laser light produced superficial necrosis and any risk of skin photosensitivity was absent by 48 hours. PDT with ALA therefore seems to be a promising technique for the treatment of superficial tumours and areas of dysplasia, as in Barrett's oesophagus. The next stage will require a more rigorous assessment of the drug and light doses, the treatment time, and mode of light delivery to optimise the PDT necrosis.

The authors thank Dr Virginia Sams, Department of Histopathology, University College Hospital, London for help in interpretation of histopathological specimens. Dr J Regula was funded by the Association for International Cancer Research with additional support from the British Council. Professor S G Bown is funded by the Imperial Cancer Research Fund.

Some of the data were published in abstract form in Gut Some of the data were
1993; 34 (suppl no 4): S19.

1 Weishaupt KR, Gomer CJ, Dougherty TJ. Identification of singlet oxygen as the cytotoxic agent in the photoactivation of a murine tumour. Cancer Res 1976; 36: 2326-9.

2 Bown SG. Photodynamic therapy to scientists and clinicians - one world or two? f Photochem Photobiol B 1990; 6: 1-12.

3 Barr H, Tralau CJ, Boulos PB, MacRobert AJ, Tilly R, Bown SG. The contrasting mechanisms of colonic collagen damage between photodynamic therapy and collagen damage between photodynamic therapy and

4 Overholt B, Panjehpour M, Tefftellar E, Rose M. Photodynamic therapy for treatment of early adenocarcinoma in Barrett's esophagus. Gastrointest Endosc 1993; 39: 73-6.

5 Harty JI, Amin M, Wieman TJ, Tseng MT, Ackerman D, Broghamer $W$. Complications of whole bladder dihaematoporphyrin ether photodynamic therapy. $\mathcal{f}$ Urol 1989; 141: 1341 .

6 Pope AJ, Bown SG. The morphological and functional changes in rat bladder following photodynamic therapy with phthalocyanine photosensitisation. F Urol 1991; 145: with phth $1064-70$.

7 Kennedy JC, Pottier RH. Endogenous protoporphyrin IX, a clinically useful photosensitizer for photodynamic therapy. F Photochem Photobiol B 1992; 14: 275-92.

8 Malik $Z$, Lugaci $H$. Destruction of erythroleukaemic cells by photoactivation of endogenous porphyrins. $\mathrm{Br} \mathcal{f}$ Cancer 1987; 56: 589-95.

9 Bedwell J, MacRobert AJ, Phillips D, Bown SG. Fluorescence distribution and photodynamic effect of ALA-induced PP IX in the DMH rat colonic tumour model. Br $\mathcal{F}$ Cancer 1992; 65: 818-24.

10 Peng Q, Moan J, Warloe T, Nesland JM, Rimington C. Distribution and photosensitizing efficiency of porphyrins Distribution and photosensitizing efficiency of porphyrins
induced by application of exogenous 5 -aminolevulinic acid in mice bearing mammary carcinoma. Int $\mathcal{f}$ Cancer 1992; 52: 433-43.

11 Grant WE, Hopper C, MacRobert AJ, Speight PM, Bown SG. Photodynamic therapy of oral cancer: photosensitisation with systemic aminolaevulinic acid. Lancet 1993; 342: 147-8.

12 Berlin NI, Neuberger A. Scott JJ. The metabolism of $\delta$-aminolaevulinic acid. 1 . Normal pathways, studied with the aid of ${ }^{15}$ N. Biochem 7 1956; 64: 80-90.

13 Loh CS, MacRobert AJ, Bedwell J, Regula J, Krasner N, Bown SG. Oral versus intravenous administration of 5-aminolaevulinic acid for photodynamic therapy. 5-aminolaevulinic acid for

14 Mustajoki P, Timonen K, Gorchein A, Seppalainen A, Matikainen E, Tenhunen $K$. Sustained high plasma 5-aminolaevulinic acid concentration in a volunteer: no porphyric symptoms. Eur $\mathcal{f}$ Clin Invest 1992; 22: 407-11.

15 Grahame Smith DG, Aronson JK, eds. Oxford textbook of clinical pharmacology and drug therapy. Oxford: Oxford University Press, 1992; 13-39.

16 Haeger-Aronsen B. Studies on urinary excretion of $\delta$-aminolaevulinic acid and other haem precursors in lead workers and lead-intoxicated rabbits. Scand $\mathcal{f}$ Clin Lab Invest 1960; 12 (suppl 47): 33-4.

17 Loh CS, Vernon DI, MacRobert AJ, Bedwell J, Bown SG, Brown SB. Endogenous porphyrin distribution induced by 5 aminolaevulinic acid in the tissue layers of the by 5 aminolaevulinic acid in the tissue layers of the
gastrointestinal tract. $\mathcal{F}$ Photochem Photobiol B 1993; 20:
47-54.

18 MacCaughan JS, Nims TA, Guy JT, Hicks WJ, Williams TE, Laufman LR. Photodynamic therapy for esophageal tumors. Arch Surg 1989; 124: 74-80.

19 Patrice T, Foultier MT, Yactayo S, Adam F, Galmiche JP, Douet MC, et al. Endoscopic photodynamic therapy with hematoporphyrin derivative for primary treatment of gastrointestinal neoplasms in inoperable patients. Dig Dis Sci 1990; 35: 545-52.

20 Lightdale C, Heier S, Marcon N, McCaughan J, Nava H, Overholt B, et al. A multicentre phase III trial of Overhoit B, et al. A multicentre phase III trial of
photodynamic therapy (PDT) vs Nd:YAG laser in the photodynamic therapy (PDT) vs Nd:YAG laser in the
treatment of malignant dysphagia. Gastrointest Endosc 1993; 39: A283.

21 Kato H, Kawaguchi M, Konaka C. Evaluation of PDT in gastric cancer. Lasers Med Sci 1986; 1: 67-74.

22 Barr H, Krasner N, Boulos PB, Chatlani P, Bown SG. Photodynamic therapy for colorectal cancer: a quantitative pilot study. Br f Surg 1990; 77: 93-6.

23 Herrera-Ornelas L, Petrelli NJ, Mittelman A, Dougherty TJ, Boyles DG. Photodynamic therapy in patients with colorectal cancer. Cancer 1986; 57: 677-84. 
24 Hochain P, Ducrotte P, Touchais JY, Paillot B. Hecketsweiler P. Extended necrosis of the oesophageal wall after photodynamic therapy: report of two cases. wall after photodynamic therapy:

25 Dougherty TJ, Cooper MT, Mang TS. Cutaneous phototoxic occurrences in patients receiving Photofrin. Lasers Surg Med 1990; 10: 485-8.

26 Ibrahim GW, Watson CJ. Enterohepatic circulation and conversion of protoporphyrin to bile pigment in man Proc Soc Exp Biol Med 1968; 127: 890-5.

27 Kondo T, Kuchiba K, Shimuzu Y. Metabolic fate of exogenous delta-aminolevulinic acid in Dubin-Johnson syndrome. F Lab Clin Med 1979; 94: 421-8.

28 Shimizu Y, Ida S, Naruto H, Urata G. Excretion of porphyrins in urine and bile after the administration of porphyrins in urine and bile after the administration of
delta-aminolevulinic acid. $\mathcal{f}$ Lab Clin Med 1978; 92: 795-802.

29 Anderson KE, Drummond GS, Freddara U, Sardana MK, Sassa S. Porphyrogenic effects and induction of heme oxygenase in vivo by $\delta$-aminolevulinic acid. Biochim Biophys Acta 1981; 676: 289-99.

30 Fukada H, Batlle AMC, Riley PA. Kinetics of porphyrin accumulation in cultured epithelial cells exposed to ALA. Int ₹ Biochem 1993; 25: 1407-10.

31 MacRobert AJ, Judd MD, Regula J, Grant WE, Bown SG Fluorescence studies of 5 -aminolaevulinic acid induced protoporphyrin IX and sulphonated aluminium phthalocyanine tissue distributions. Proc SPIE 1993; 2081: 33-40.

32 Van Hillegersberg R, Van den Berg JWO, Kort WJ, Terpstra OT, Wilson JHP. Selective accumulation of endogenously produced porphyrins in a liver metastasis model in rats. Gastroenterology 1992; 103: 647-51.

33 Batlle del C AM. Porphyrins, porphyrias, cancer and photodynamic therapy - a model for carcinogenesis. photodynamic therapy - a model

34 Sampliner RE, Hixson LJ, Fennerty MB, Garewal HS Regression of Barrett's esophagus by laser ablation in an anacid environment. Dig Dis Sci 1993; 38: 365-8.

35 Gorchein A. Webber R. ס-Aminolaevulinic acid in plasma, cerebrospinal fluid, saliva and erythrocytes: studies in normal, uraemic and porphyric subjects. Clin Sci 1987; 72: 103-12. 